\title{
Taxonomic Position of the Oriental Species of Mesosa (Mesosa) (Coleoptera, Cerambycidae, Lamiinae, Mesosini)
}

\author{
Junsuke Yamasako $^{1}$ and Nobuo Ohbayashi ${ }^{2}$ \\ ${ }^{1}$ Entomological Laboratory, Faculty of Agriculture, Ehime University, Tarumi, Matsuyama 790-8566, Japan \\ ${ }^{2}$ Kamimiyada 1334-444, Minamishitaura-machi, Miura 238-0101, Japan
}

Correspondence should be addressed to Junsuke Yamasako, mesoxxmesosa@hotmail.com

Received 9 September 2011; Accepted 25 October 2011

Academic Editor: Michael Rust

Copyright (C) 2012 J. Yamasako and N. Ohbayashi. This is an open access article distributed under the Creative Commons Attribution License, which permits unrestricted use, distribution, and reproduction in any medium, provided the original work is properly cited.

\begin{abstract}
Twelve oriental mesosine species which had been belonged to the nominotypical subgenus of the genus Mesosa Latreille, 1829, are transferred to the subgenus Dissosira Pascoe, 1865 of the genus Agelasta Newman, 1842, as follows: A. (D.) perplexa (Pascoe, 1858); A. (D.) columba (Pascoe, 1859); A. (D.) rufa (Breuning, 1935); A. (D.) catenatoides Yamasako and N. Ohbayashi, nom. nov. [replacement name for A. (D.) laosensis (Breuning, 1935) already occupied by Pic (1925)]; A. (D.) gardneri (Breuning, 1938); A. (D.) nigropunctata (Breuning, 1938); A. (D.) konoi (Hayashi, 1956); A. (D.) yonaguni (Hayashi, 1962); A. (D.) nigrostictica (Breuning, 1967); A. (D.) siamana (Breuning, 1974); A. (D.) praelongipes (Kusama and Irie, 1976); A. (D.) kumei (Takakuwa, 1991).
\end{abstract}

\section{Introduction}

The genus Mesosa was erected by Latreille [1] on the basis of two Palearctic species, Cerambyx curculionoides Linnaeus, 1761 and Lamia nebulosa Fabricius, 1781, of which the former was designated as the type species of the genus. Later, Breuning [2] divided the genus Mesosa into six subgenera as follows: Mesosa (Mesosa) Latreille 1829; M. (Aphelocnemia [sic]) Stephens, 1831; M. (Saimia) Pascoe, 1866; M. (Anthlyboscila) Thomson, 1868; M. (Perimesosa) Breuning, 1939; M. (Metamesosa) Breuning, 1939. Recently, Yamasako and Ohbayashi [3] erected a new subgenus, $M$. (Lissomesosa), and they also [4] synonymized M. (Anthlyboscila) with Agelasta (Dissosira) Pascoe, 1865. As a result, the genus Mesosa now consists of six subgenera and includes more than 80 species.

Among the subgenera, Mesosa (Mesosa) is the nominotypical subgenus and comprised of 19 species until now. However, as a result of our close examination of the external and male genital features, they are considered to be polyphyletic and could be separated into some species groups. Of those, one group, including the name-bearing type M. curculionoides (Linnaeus, 1761), is the true nominotypical species group and is distributed throughout the Palearctic region.
On the other hand, the 12 oriental species are a different phyletic line from the Palearctic species group and are closely related to the subgenus Dissosira Pascoe, 1865, of the genus Agelasta Newman, 1842.

As we have already pointed out in a previous paper (Yamasako and Ohbayashi [4]), the hitherto distinguishable feature between Mesosa and Agelasta, the rounded or truncated prosternal process in lateral view, is not a suitable characteristic, and many species in the genus Mesosa have been confused with the genus Agelasta because of this problem. According to other external features and the endophallic structures, the 12 species distributed in the Oriental region should be transferred to Agelasta (Dissosira) in spite of their rounded prosternal process. Therefore, we herein propose them to be transferred from Mesosa (Mesosa) to Agelasta (Dissosira). This is the ninth part of our studies on the Asian Mesosini.

\section{Materials and Methods}

This study was conducted based on the dried specimens preserved in the following public collections, our private collections, and also the collections of friends. 
BMNH: The Natural History Museum, London, UK. EUMJ: Ehime University Museum, Matsuyama, Japan.

MNHN: Muséum National d'Histoire Naturelle, Paris, France.

ZSM: Zoologische Staatssammlung München, Munich, Germany.

The verbatim label data indicated by double quotation marks (") ) are given for the type materials, and the line breaks of the label are indicated by a slash (/).

The observational method and the corresponding terms of endophallus should be referred to Yamasako and Ohbayashi [5].

\section{Systematics}

Agelasta (Dissosira) Pascoe, 1865

Type species. Agelasta catenata Pascoe, 1862 (Figures 1(d)-1(f), 2(c)-2(d), 3(a)-3(b), 6(a), 7(a)-7(d), and 9(a)).

Dissosira Pascoe, 1865. 124, note [6].

Chaeromorpha (Dissosira): Aurivillius, 1922: 145 [7].

Agelasta (Dissosira): Breuning, 1939: 482 [2].

Anthriboscyla Thomson, 1868. 165 [8]; type species: Anthriboscyla mima Thomson, 1868.

Mesosa (Anthriboscyla): Breuning, 1939: 411 [2].

Pseudaemocia Breuning, 1935. 269 [9]; type species: Pseudaemocia rufa Breuning, 1935 syn. nov.

Mutatocoptops (Pseudaemocia): Breuning, 1939: 506 $[2]$.

Redescription (Modified the Diagnosis of Yamasako and Ohbayashi [4]). Body ovoid in shape; eyes subdivided; lower lobes relatively large, slightly wider than long. Antennal tubercles hardly elevated. Antennae well long and thick; each segment without apical spine, fringed beneath by suberect short setae; scape well long, slightly thickened apically, with a well-developed cicatrix on the apex; third segment distinctly longer than scape and fourth, respectively. Pronotum wider than long, with some indistinct discal tubercles; each side near apical margin usually with a small dull projection. Prosternal process with extremity usually well swollen posteroventrally, almost truncate in lateral view, but sometimes hardly swollen and more or less roundly sloped in lateral view. Mesosternal process with a well-developed tubercle on the center near the apex and roundly projected anteroventrally, almost truncate in lateral view.

Elytra without basal high bosses and lacking long suberect hairs. Legs with mesotibiae without distal notch on anterior side.

Endophallus. Endophallus well long and slender, approximately three times as long as median lobe, divided into $\mathrm{BPH}$,
$\mathrm{MPH}$, and APH, with three kind spicule like sclerites as MSp, LSp, and SSp. BPH nearly 0.2 times as long as endophallus. $\mathrm{MPH}$ nearly 0.7 times as long as endophallus, subdivided into two membrane subdivisions as almost fused MT+CT and $\mathrm{PB}$ by a distinct constriction. APH well swollen and oval bursiform, nearly 0.2 times as long as endophallus, with ED on dorsal side, usually with AA which is lingulate shape and laid near ED, without AS.

MSp usually distributed in nearly apical half of MT+CT. LSp usually distributed in nearly basal half of MT+CT; dorsal side ones thick and short, arranged into two irregular longitudinal lines, unidentate in apical area, thence becoming thicker, denser, and multidentate toward basal area; ventral side ones rudimentary unidentate, and disappeared in some cases. SSp unidentate, short, and small, covered almost entire area of PB. MSp area and LSp area adjacent. LSp area and SSp area are separated but close to each other.

Remarks. Up to the present time, the genus Agelasta includes over 70 species which are separated into nine subgenera. Agelasta (Dissosira) has mainly been distinguished from the other subgenera by the following features (Breuning [2]): (1) pronotum without five distinct tubercules on disk, (2) elytra with basal margin not forming transversal edge, without high bosses near base and long suberect setae throughout, (3) humeri weakly projected laterad, (4) prosternal process well truncated in lateral view.

As already indicated by Yamasako and Ohbayashi [4], 24 known species belonging to the subgenus Dissosira could be separated into some species groups based on the external and male genital features. The redescription above is based on the type species group of the subgenus (Yamasako and Ohbayashi [4]).

The Species Transferred from Mesosa (Mesosa) to Agelasta (Dissosira). The following 12 species which are classified into Mesosa (Mesosa) are distinctly different from the type species of the subgenus, M. (M.) curculionoides (Figures 1(a)-1(c), $2(\mathrm{a})-2(\mathrm{~b}))$ in the external features and the endophallic structures. These characteristics well coincide with Agelasta (Dissosira) except for the rounded prosternal process.

\subsection{Agelasta (Dissosira) perplexa (Pascoe, 1858), Comb. Nov.}

(Figures 3(c)-3(d), 6(b), 7(e)-7(h), and 9(b))

Mesosa perplexa Pascoe, 1858: 243 [6].

Pachyosa perplexa: Matsushita, 1933: 344 [10].

Mesosa (Mesosa) perplexa: Breuning, 1939: 401 [2].

Saimia alternans Schwarzer, 1925: 60 [11].

Mimocoptops? formosana Pic, 1925: 30 [12].

Diagnosis. Body black, covered with ocher pubescence. Occiput with four narrow longitudinal black bands. Antennae with each basal part of third to the last segments with white pubescent annulations though it is very narrow on fifth, seventh, and ninth segments. Pronotum with three longitudinal narrow black bands on disk. Elytra with two light yellowish 


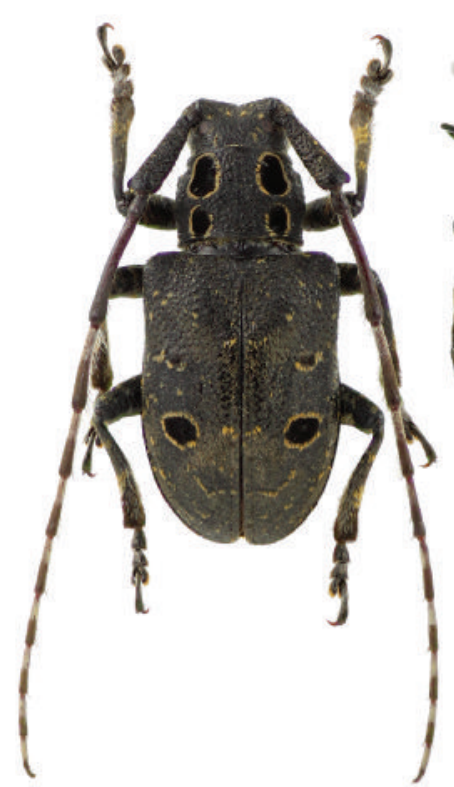

(a)

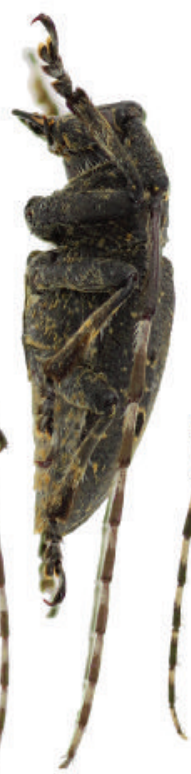

(b)

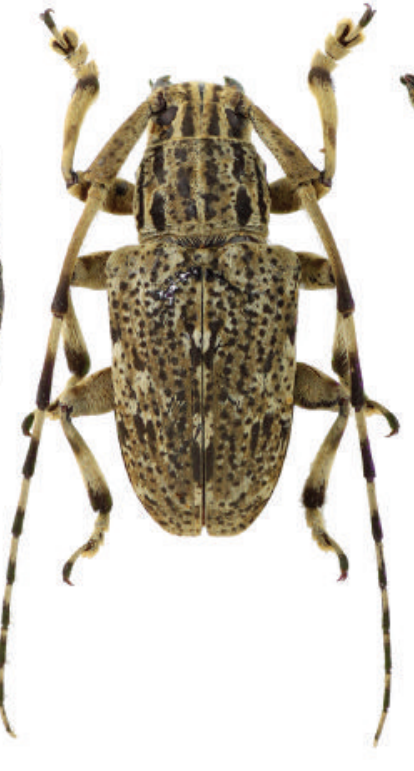

(d)

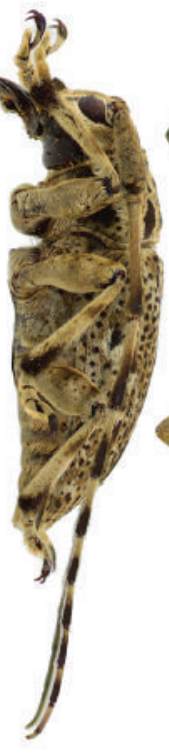

(e)

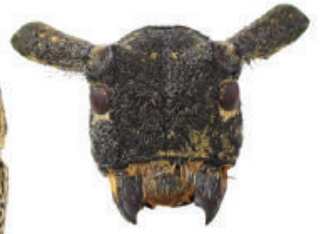

(c)

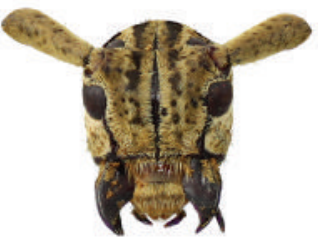

(f)

Figure 1: Comparison of the type species of Mesosa (Mesosa) and Agelasta (Dissosira). (a-c) M. (M.) curculionoides; (d-f) A. (D.) catenata; (a, d) male habitus in dorsal view; (b, e) ditto in lateral view; $(c, f)$ ditto in frontal view.

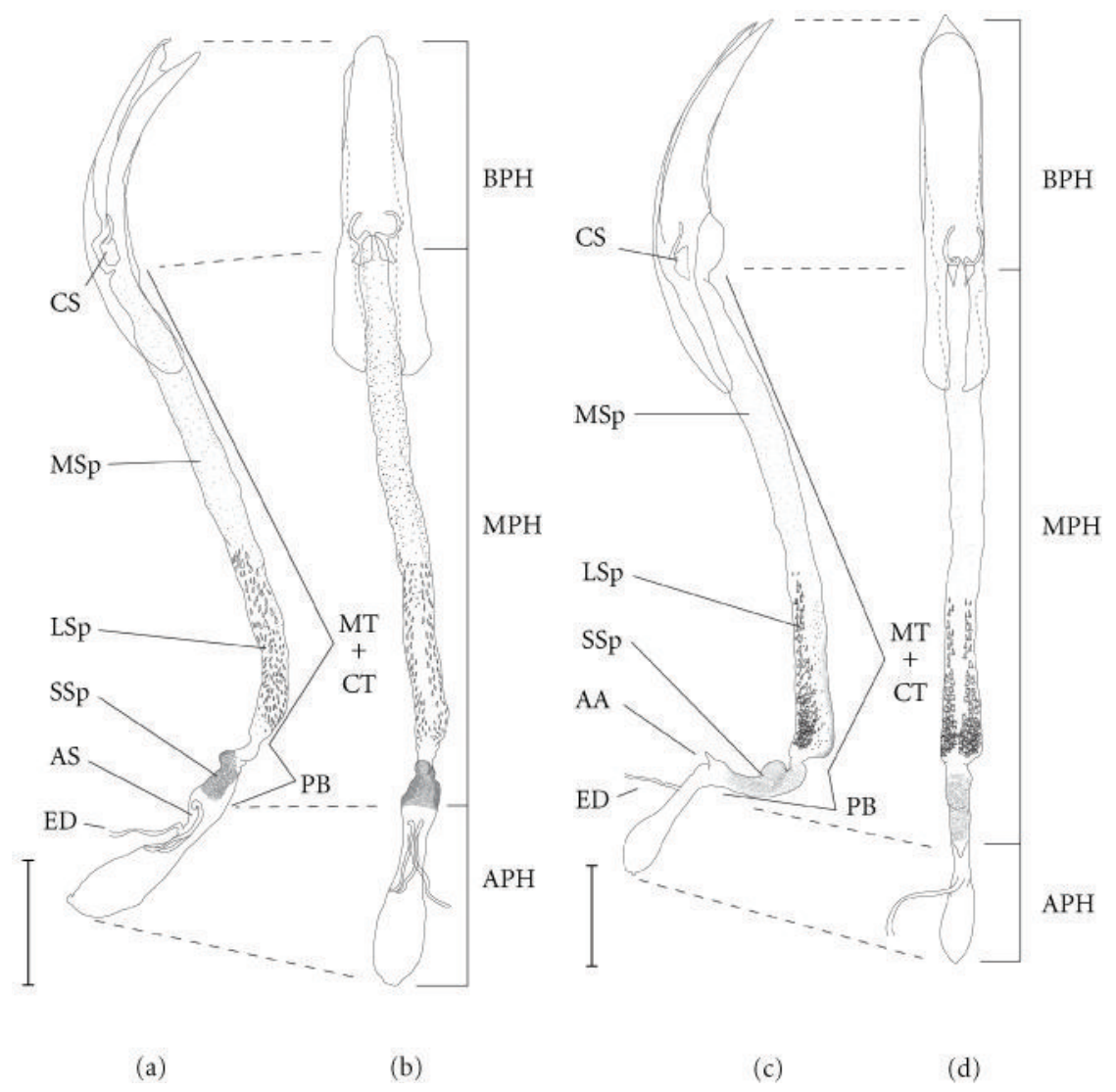

Figure 2: Comparison of the type species of Mesosa (Mesosa) and Agelasta (Dissosira). (a, b) M. (M.) curculionoides; (c, d) A. (D.) catenata; $(\mathrm{a}, \mathrm{c})$. median lobe with endophallus in lateral view; (b, d) ditto in dorsal view. Scale: $1.0 \mathrm{~mm}$. For abbreviations see text. 


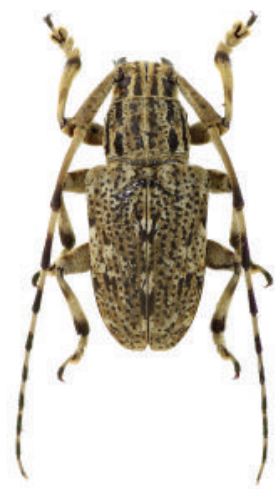

(a)

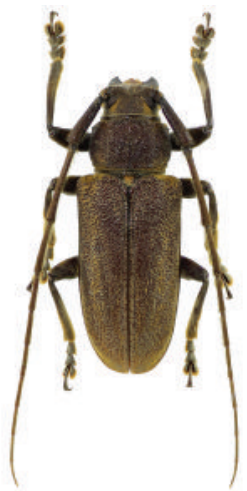

(e)

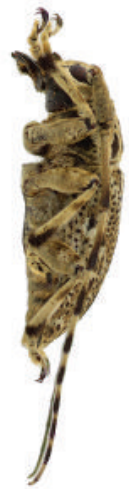

(b)

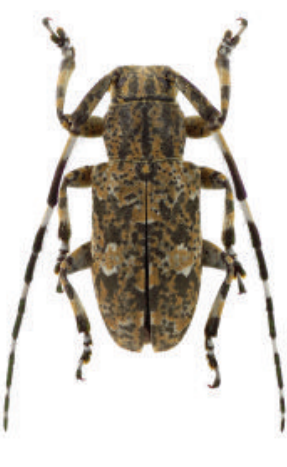

(c)

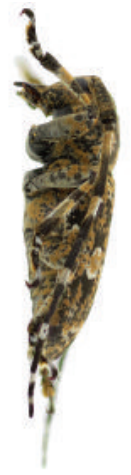

(d)

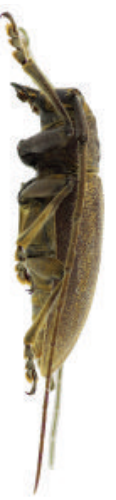

(f)

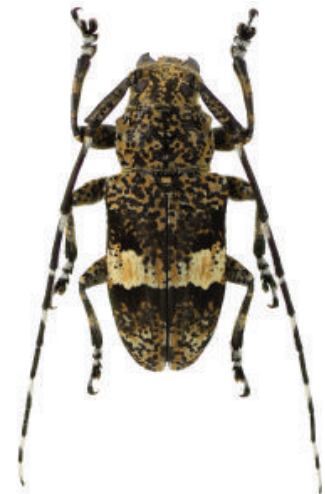

(g)

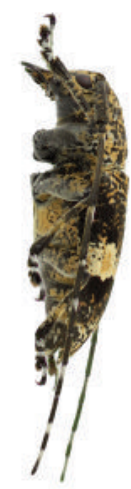

(h)

Figure 3: Male habitus of Agelasta (Dissosira) spp. (a, b) A. (D.) catenata; (c, d) A. (D.) perplexa; (e, f) A. (D.) rufa; (g, h) A. (D.) konoi; (a, c, e, g) dorsal view; (b, d, f, h) lateral view.

or whitish brown bands which are marginated with black irregular spots. Prosternal process roundly sloped and not truncate in lateral view.

Male Genitalia $(n=2)$. Tegmen in lateral view slightly curved, slender rhombic, and widest near middle in ventral view. Ringed part slightly expanded laterad at near middle of tegmen, thence arcuately narrowed basad. Lateral lobes about $1 / 3$ of total length of tegmen, with inner sides almost straight and outer sides nearly straight toward apical third, thence slightly narrowed to angularly rounded apex, provided with two kinds of setae of which one is long and thick, concentrated near apex, and another is rather short and thin, arising chiefly from outer sides of apical half.

Median lobe in lateral view gentry curved; apex in ventral view weakly pointed; median strut dehiscent from basal 2/5.

Endophallus almost three times as long as median lobe in lateral view. The relative length of each broad membrane area of endophallus to median lobe are as follows: ML: TLE: BPH: MPH (MT+CT:PB): APH $=3.7: 10.0$ : $2.2: 5.9(5.0: 0.8): 2.0$. MPH with MT+CT well swollen and projected on ventral side near base. APH well swollen in oval shape, with ligulate shaped AA near apex.
MSp distributed in nearly apical $2 / 3$ of MT+CT. LSp distributed in almost basal $1 / 3$ of MT+CT on dorsal side, thick and short, arranged into two longitudinal irregular lines, unidentate in apical area, thence becoming thicker, denser, and multidentate toward basal area. SSp short, small and unidentate, covered almost of laterodorsal side and basal 1/3 of ventral side of PB. MSp area and LSp area adjacent. LSp area and SSp area close to each other.

Specimens Examined. [China] Syntype (BMNH): 19, "China" [printed on green oval label]; "Type" [printed on white label with red circle]; "Mesosa/perplexa/Pasc/N. China" [printed on white label]; "Pascoe/Coll./93-60." [printed on white label]; "Mesosa/perplexa/China Pasc." [printed on white label]; $10^{7}$, She Shan, Shanghai, 9. VII, 2002, Hu and Tang leg. [Taiwan]: 10', Shouka forest road, Shizi township, Pingtung county, 4. VII, 2006, S-T. Hisamatsu leg. [Japan]: $30^{7} 0^{7}, 3$ 우, Yanaimachi, Matsuyama City, Ehime Pref., 20. VI, 1997, N. Ohbayashi leg.; 107, Shindate, Matsuyama City, Ehime Pref., 2. XI, 2004, J. Yamasako leg.; $10^{\pi}$, same locality, 10. XI, 2004, J. Yamasako leg.

Distributions. China, Taiwan, Japan. 


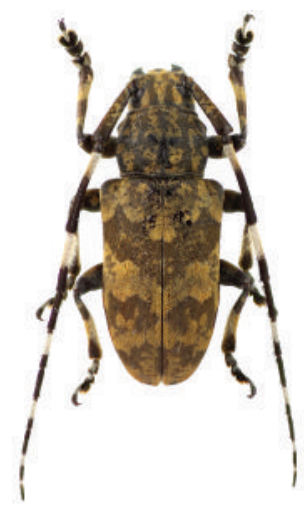

(a)

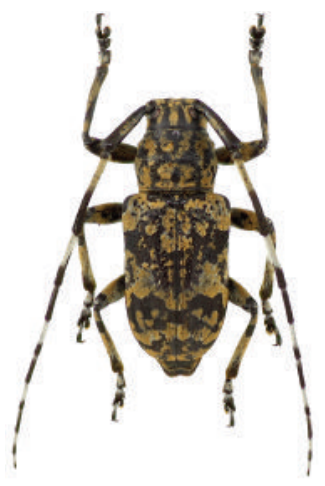

(e)

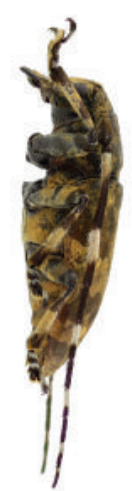

(b)

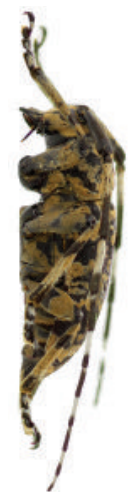

(f)

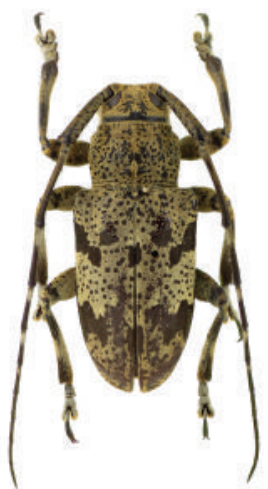

(c)

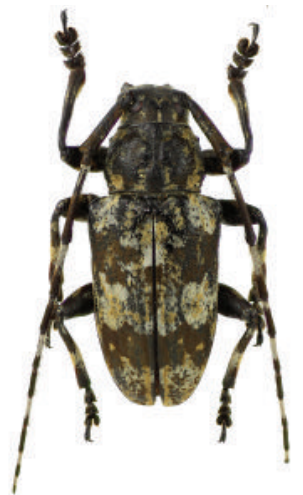

(g)

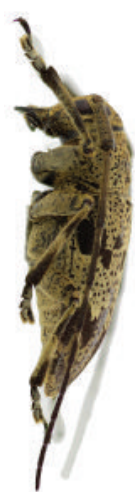

(d)

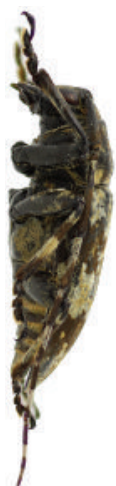

(h)

Figure 4: Male habitus of Agelasta (Dissosira) spp. (a, b) A. (D.) yonaguni; (c, d) A. (D.) nigrostictica; (e, f) A. (D.) praelongipes; (g, h) A. (D.) kumei; (a, c, e, g) dorsal view; (b, d, f, h). lateral view.

3.2. Agelasta (Dissosira) columba (Pascoe, 1859), Comb. Nov.

(Figure 5(a))

Mesosa columba Pascoe, 1859: 40 [6].

Mesosa (Mesosa) columba: Breuning, 1939: 402 [2].

Diagnosis. This species is similar to A. perplexa, but distinguishable by the following features. Body black, covered with light brown pubescence. Pronotum with two pair of small rounded black maculae on disk. Elytra with several white spots which are sometimes forming transversal band near middle, scattered with some spots of dark brown pubescence which are sometimes forming indistinct transversal band before and after middle of elytra. Prosternal process roundly sloped and not truncate in lateral view.

Specimen Examined. Syntype (BMNH): 10", "Ceylon" [printed on light blue circle label]; "Mesosa/columba/Pascoe/ type" [printed on white label]; "Type" [printed on white label with red circle].

\section{Distribution. Sri Lanka.}

Remarks. No specimen was available for dissection of male genitalia. However, this species distinctly differs from Mesosa
(Mesosa) in the following structures: antennal scape elongate and slightly thickened apically; lower eye lobe relatively large. Besides, the external characteristics of this species are similar to A. perplexa and well coincided with Agelasta (Dissosira). Therefore, we treat this species as a member of this subgenus.

\subsection{Agelasta (Dissosira) rufa (Breuning, 1935), Comb. Nov.}

(Figures 3(e)-3(f), 6(c), 7(i)-7(1), and 9(c))

Pseudaemocia rufa Breuning, 1935: 269 [9].

Mutatocoptops (Pseudaemocia) rufa: Breuning, 1939: 506 [2].

Mesosa (Mesosa) rufa: N. Ohbayashi, 1992: 8 [13].

Diagnosis. Body reddish brown, sparsely covered with yellowish pubescence. Elytra sparsely with spots of yellowish pubescence which are sometimes forming some irregular longitudinal narrow maculae. Prosternal process rounded and not truncate at the apex.

Male Genitalia $(n=2)$. Tegmen in lateral view slightly curved, rhombic, and widest near middle in ventral view. Ringed part slightly expanded laterad at near middle of tegmen, thence arcuately narrowed basad. Lateral lobes about $1 / 4$ of 


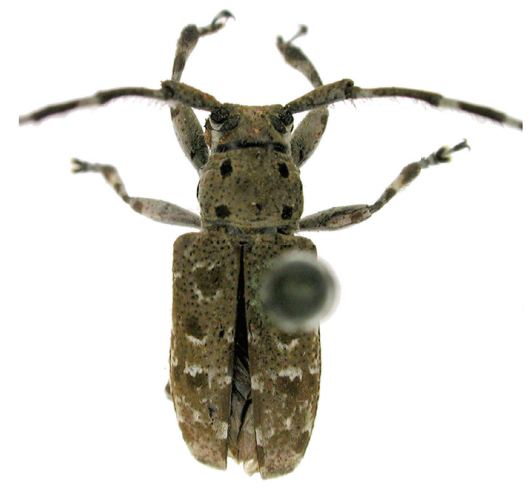

(a)

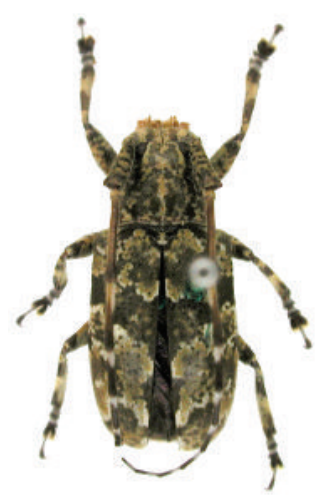

(c)

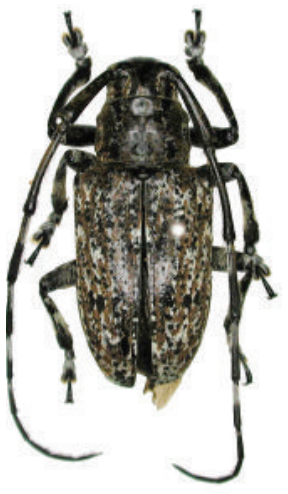

(d)

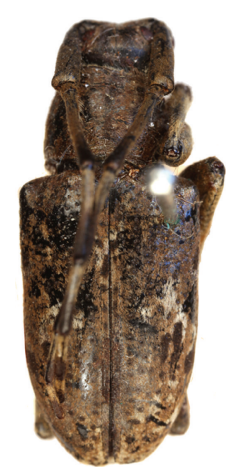

(b)

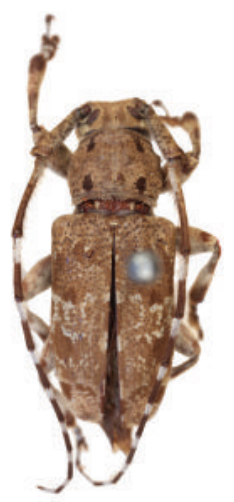

(e)

Figure 5: Habitus of Agelasta (Dissosira) spp. in dorsal view. (a) A. (D.) columba (syntype); (b) A. (D.) catenatoides (holotype); (c) A. (D.) gardneri (holotype); (d) A. (D.) nigropunctata; (e) A. (D.) siamana (holotype).

total length of tegmen, with inner sides almost straight and outer sides gently narrowed to rounded apex, provided with two kinds of setae of which one is long and thick, concentrated near apex, and another is rather short and thin, arising chiefly from outer sides of apical half.

Median lobe in lateral view gentry curved; apex in ventral view weakly pointed; median strut dehiscent from basal 1/3.

Endophallus almost 2.5 times as long as median lobe in lateral view. The relative length of each broad membrane area of endophallus to median lobe are as follows: ML: TLE: BPH : MPH (MT+CT : PB) $:$ APH $=4.1: 10.0: 2.3: 5.9(4.9$ : $1.0): 1.8$. MPH with MT+CT well swollen and projected on ventral side near base. APH well swollen in oval shape, with ligulate-shaped AA near apex.

MSp distributed in nearly apical $2 / 3$ of MT+CT. LSp distributed in almost basal $1 / 3$ of MT+CT on dorsal side, thick and short, arranged into two longitudinal irregular lines, unidentate in apical area, thence becoming thicker, denser, and multidentate toward basal area. SSp unidentate, short and small, covered almost of laterodorsal side and basal $1 / 3$ of ventral side of PB. MSp area and LSp area adjacent. LSp area and SSp area slightly separated each other.

Specimens Examined. Holotype (BMNH): 19, "Parry's Group/Bonin I./91-25" [printed on white label]; "Type" [printed on white label with red circle]; "Pseudaemocia/rufa mihi/Typ!/det. Breuning" [printed on white label]. Ogasawara Isls., Tokyo Pref., Japan, [Is. Chichijima]: 1ㅇ, 25. X, 1974, M. Iga leg. [Is. Hahajima]: 10 , 3oo, Chibusa-yama, 15. VI, 1992, N. Ohbayashi leg.; 10', Okimura, 16. VI, 1992, N. Ohbayashi leg.; 10', Mt. Funaki, 16. VI, 1991, T. Ito leg.; 1, 17. V, 1984, M. Hasegawa leg.; 107, 2oㅇ, 15-17. VI, 1985, H. Makihara leg.; 10', 2oㅇ, Funamidai, 24-27, VI. 1987, M. Nishimura leg.; 10', 19, Motochi, 25, VI. 1987, M. Nishimura leg. [Is. Mukojima]: 10', 19. X, 2002, H. Karube leg.

Distribution. Japan (Ogasawara Isls.).

Remarks. This species is endemic to the Ogasawara Islands, Japan. It was first described based on a female specimen as a unique species of the genus Pseudaemocia Breuning, 1935, which was downgraded to a subgenus of Mutatocoptops Pic, 1925 by Breuning [2]. Later, Ohbayashi [13] transferred it to Mesosa (Mesosa) by reason of the resemblance of its larval characters to $M$. (M.) yonaguni. In spite of its unique appearance of reddish body, very rough punctures on the body and indistinct maculae on the elytra, this species has male genital structures almost in common with M. (M.) yonaguni, and the external features basically coincide with the congeners of 


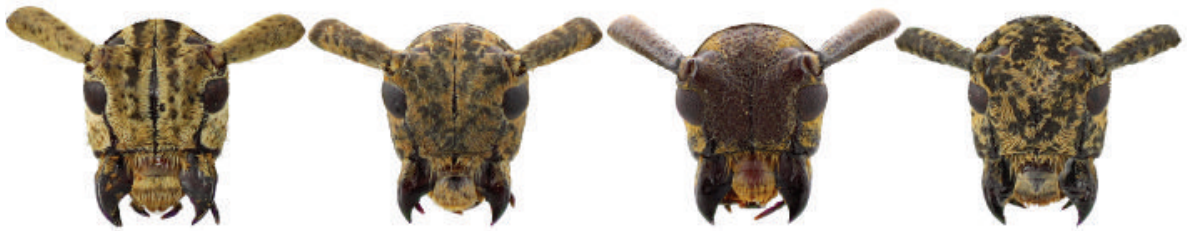

(a)

(b)

(c)

(d)

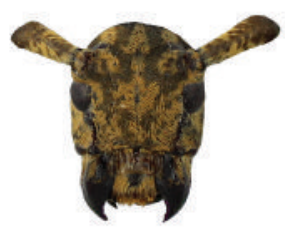

(e)

(f)

(g)

(h)

Figure 6: Male frontal view of Agelasta (Dissosira) spp. (a) A. (D.) catenata; (b) A. (D.) perplexa; (c) A. (D.) rufa; (d) A. (D.) konoi; (e) A. (D.) yonaguni; (f) A. (D.) nigrostictica; (g) A. (D.) praelongipes; (h) A. (D.) kumei.

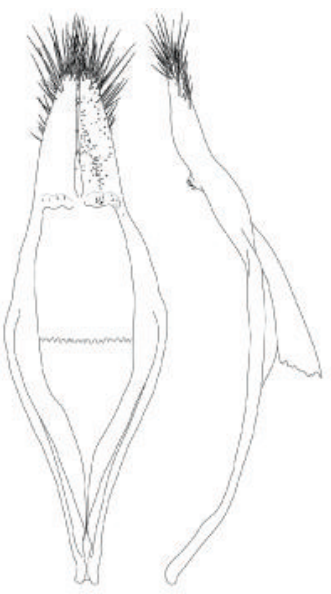

(a)

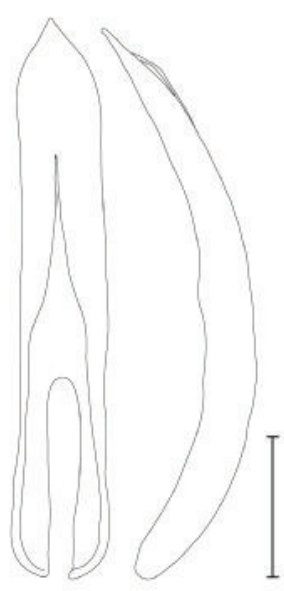

(c)

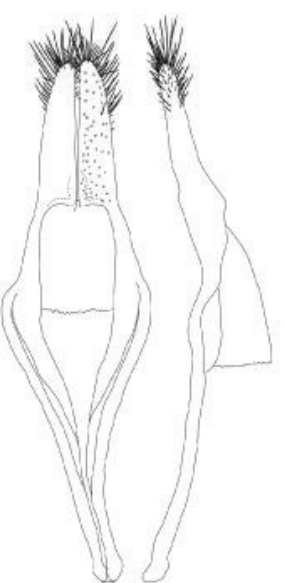

(e)

(f)

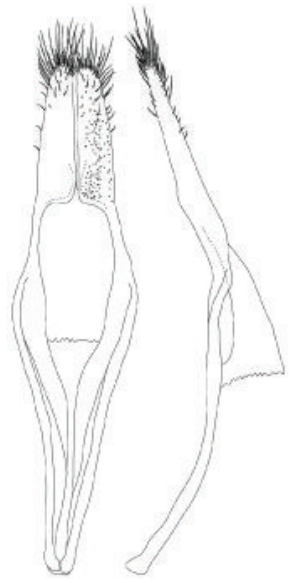

(m)

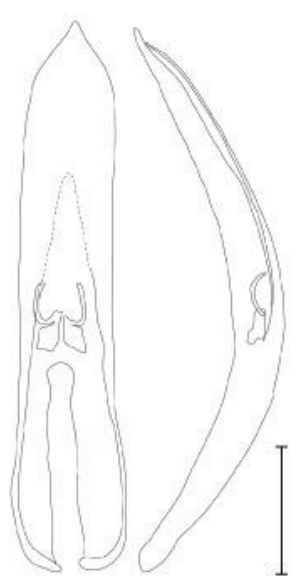

(k)

(l)

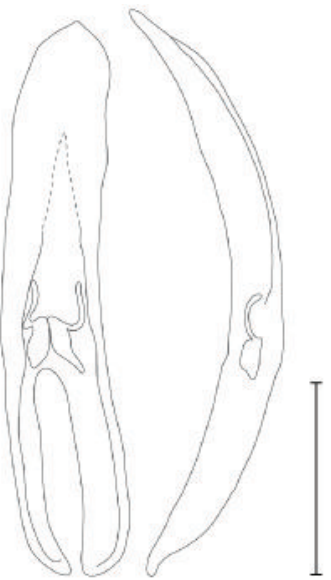

(g)

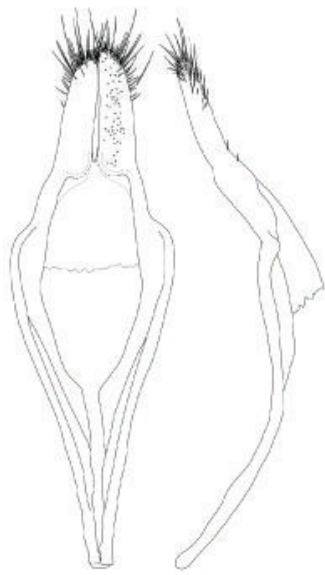

(i)

(j)

Figure 7: The male genital organ of Agelasta (Dissosira) spp. (a-d) A. (D.) catenata; (e-h) A. (D.) perplexa; (i-l) A. (D.) rufa; (m-p) A. (D.) konoi; (a, e, i, m) tegmen in ventral view; (b, f, j, n) ditto in lateral view; (c, g, k, o) median lobe in ventral view; (d, h, l, p). ditto in lateral view. Scale: $1.0 \mathrm{~mm}$. 


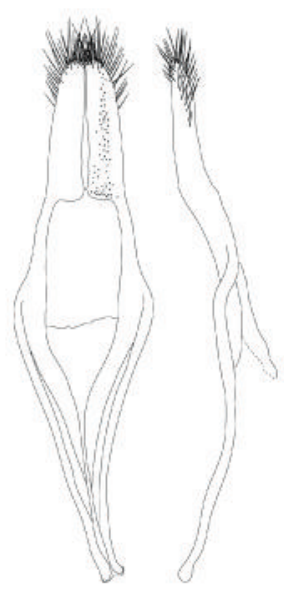

(a)

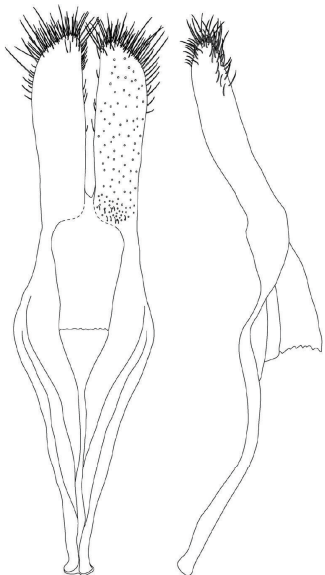

(i)

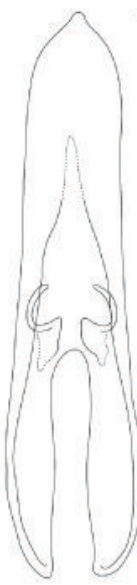

(c)

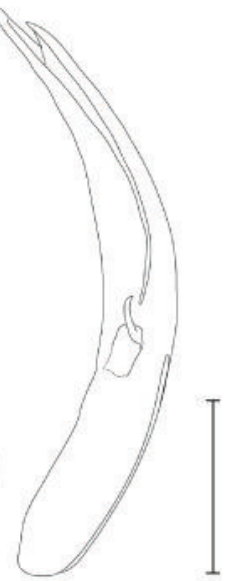

(d)

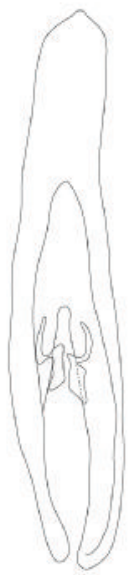

(k)

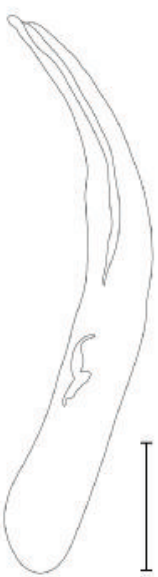

(1)

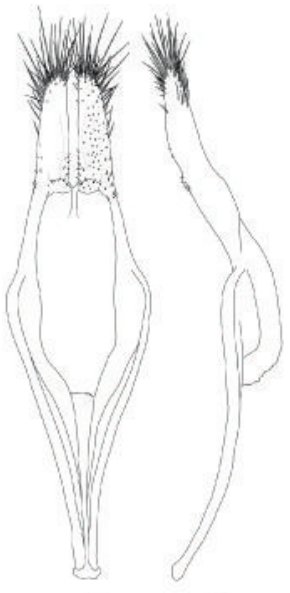

(e)

(f)

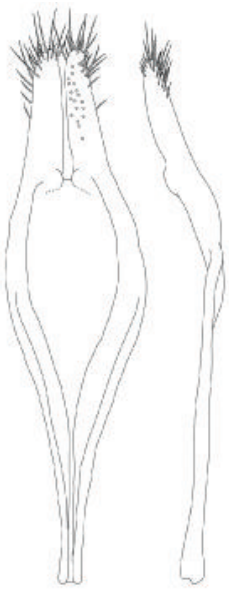

$(\mathrm{m})$

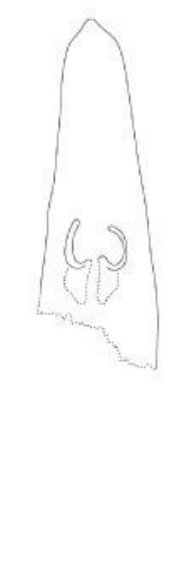

(o)

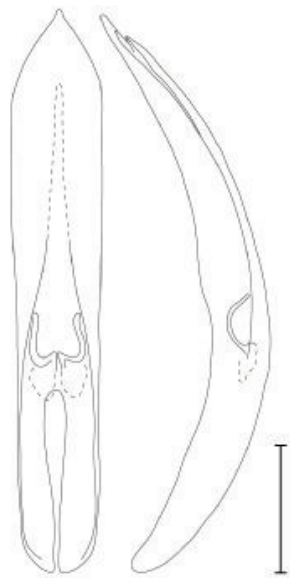

(h)

Figure 8: The male genital organ of Agelasta (Dissosira) spp. (a-d) A. (D.) yonaguni; (e-h) A. (D.) nigrostictica; (i-l) A. (D.) praelongipes; $(\mathrm{m}-\mathrm{p})$ A. (D.) kumei; (a, e, i, m) tegmen in ventral view; (b, f, j, n) ditto in lateral view; $(\mathrm{c}, \mathrm{g}, \mathrm{k}, \mathrm{o})$ median lobe in ventral view; $(\mathrm{d}, \mathrm{h}, \mathrm{l}, \mathrm{p})$ ditto in lateral view. Scale: $1.0 \mathrm{~mm}$.

Agelasta (Dissosira). Therefore, we treat this species as a member of this subgenus.

\subsection{Agelasta (Dissosira) catenatoides Yamasako and N. Ohba-} yashi, Nom. Nov. (Nomen Preoccupied by Agelasta laosensis Pic, 1925) (Figure 5(b))

Mesosa laosensis Breuning, 1935: 274 [9].

Mesosa (Mesosa) laosensis: Breuning, 1939: 402 [2].

Diagnosis. This species is quite similar to A. catenata, but distinguishable by body covered with brown pubescence.

Specimen Examined. Photographs of the holotype (MNHN): $\sigma^{7}$, "Mesosa/laosensis/mihi Typ/det. Breuning" [printed on white label], "Vieng Kiet/5. oct. 1915/Vitalis" [printed on white label], "type" [printed on yellow label], "laosensis Br." [printed on white label], "TYPE” [printed on red label].
Distribution. Laos.

Remarks. No specimen was available for dissection of the male genitalia. The diagnosis described above is based on some photographs of the holotype. Judging from the photographs, this species is without doubt close to $A$. (D.) catenata which is the type species of Agelasta (Dissosira). Therefore, we treat this species as a member of Agelasta (Dissosira). On the other hand, the species name, Agelasta laosensis, is already occupied by Pic [12], and A. laosensis (Breuning, 1935 nec Pic, 1925) should be replaced by the secondary homonym. Therefore, we propose a new replacement name, $A$. (D.) catenatoides nom. nov., for the latter. The specific epithet refers to the resemblance to $A$. (D.) catenata.

\subsection{Agelasta (Dissosira) gardneri (Breuning, 1938), Comb.} Nov. (Figure 5(c))

Mesosa gardneri Breuning, 1938: 204 [14].

Mesosa (Mesosa) gardneri: Breuning, 1939: 402 [2]. 


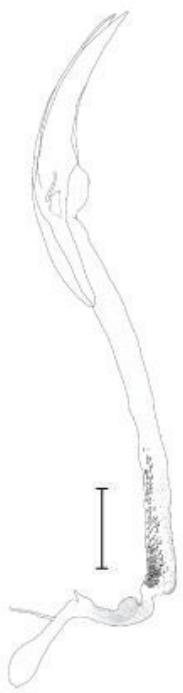

(a)

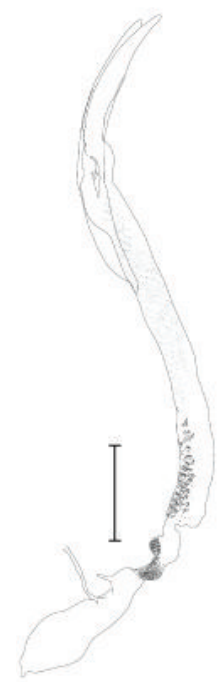

(b)

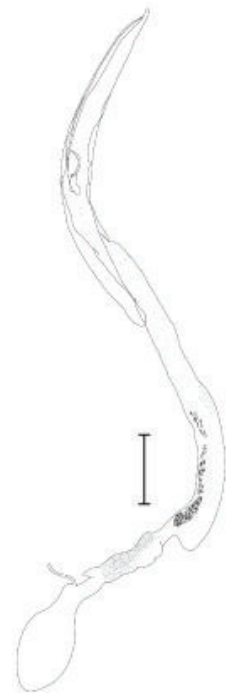

(c)

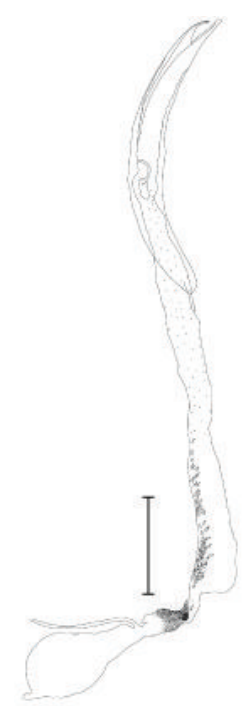

(d)

Figure 9: The median lobe with endophallus of Agelasta (Dissosira) spp. in lateral view. (a) A. (D.) catenata; (b) A. (D.) perplexa; (c) A. (D.) rufa; (d) A. (D.) konoi. Scale: $1.0 \mathrm{~mm}$.

Diagnosis. This species is similar to A. perplexa, but distinguishable by the following features. Body black, mingled with light and dark brown pubescence. Antennae with each basal part of third to the last segments with white pubescent annulations, which are getting narrower toward the last segment. Elytra with indistinct transversal bands of light brown pubescence near base and after middle, indistinct dark brown transversal bands before middle and near apices, scattered with white spots.

Specimen Examined. Holotype (BMNH): "Lachiwala/Dehra Dun, U. P./F. Ent./17. VII. 1929" [printed on white label], "R. R. D. 892/B. C. R. 284/Cage 712" [printed on white label], "Ex Bauhinia/retusa." [printed on white label], "37” [printed on white label], "Mesosa/gardneri/mihi Type/det. Breuning" [printed on white label], "Type" [printed on white circle label with red margined].

\section{Distribution. North India.}

Remarks. No specimen was available for dissection of the male genitalia. However, this species basically shares external characteristics with $A$. (D.) perplexa. Therefore, we treat this species as a member of Agelasta (Dissosira).

\subsection{Agelasta (Dissosira) nigropunctata (Breuning, 1938),}

Comb. Nov. (Figure 5(d))

Mesosa nigropunctata Breuning, 1938: 203 [14].

Mesosa (Mesosa) nigropunctata: Breuning, 1939: 402 [2].

Diagnosis. This species is very similar to A. catenata, but distinguishable by the following features. Body black, mingled with black, brown, and white pubescence. Occiput with four narrow longitudinal black bands. Antennae with each basal part of third to 7th segments with white pubescent annulations, which are getting narrower toward 7th segment; the reminders covered with black pubescence. Pronotum with two longitudinal narrow black bands on disk. Elytra irregularly scattered with longitudinal spots of black, brown, and white pubescence. Prosternal process roundly sloped and not truncate in lateral view.

Specimen Examined. 10', Mulayit Taung, SE-Burma, 11, 1989 (ZSM, determined by Hüdepohl in 1995).

\section{Distribution. Myanmar.}

Remarks. No specimen was available for dissection of the male genitalia. However, this species basically shares external characteristics with $A$. (D.) catenata which is the type species of Agelasta (Dissosira). Therefore, we treat this species as a member of Agelasta (Dissosira).

\subsection{Agelasta (Dissosira) konoi (Hayashi, 1956), Comb. Nov.}

Remarks. This species is mainly distributed in the northeastern part of the Ryukyu Islands, Japan, and is divided into five subspecies as described below. Here we limited the description to the nominotypical subspecies only, and that of the other subspecies are omitted.

3.7.1. Agelasta (Dissosira) konoi konoi (Hayashi, 1956), Comb. Nov. (Figures 3(g)-3(h), 6(d), 7(m)-7(p), and 9(d))

Mesosa (Mesosa) konoi Hayashi, 1956: 13, pl. 4, Figure $1[15]$. 
Mesosa (Mesosa) konoi konoi: Hayashi, 1962: 33 [16].

Diagnosis. This species is similar to A. perplexa, but distinguishable by the following features. Body black, covered with ocher pubescence. Elytra with a yellowish white maculae marginated with black pubescence near middle.

Male Genitalia $(n=2)$. Tegmen in lateral view slightly curved, slender rhombic, and widest near middle in ventral view. Ringed part slightly expanded laterad near middle of tegmen, thence arcuately narrowed basad. Lateral lobes about 1/4 of total length of tegmen, with inner sides almost straight, and outer sides nearly straight toward apical third, thence slightly narrowed to rounded apex, provided with two kinds of setae of which one is long and thick, concentrated near apex, and another is rather short and thin, arising mainly from laterodorsal sides of apical half.

Median lobe in lateral view gentry curved; apex in ventral view weakly pointed; median strut dehiscent from basal 2/5.

Endophallus almost three times as long as median lobe in lateral view. The relative length of each broad membrane area of endophallus to median lobe is as follows: ML: TLE: $\mathrm{BPH}: \mathrm{MPH}(\mathrm{MT}+\mathrm{CT}: \mathrm{PB}): \mathrm{APH}=3.5: 10.0: 2.1: 6.1$ (5.5: $0.6)$ : 1.9. MPH with MT+CT well swollen and projected on ventral side near base. APH well swollen in oval shape, with ligulate-shaped AA near apex.

MSp distributed in nearly apical half of MT+CT. LSp distributed in nearly basal half of MT+CT on dorsal side, thick and short, arranged into two longitudinal irregular lines, unidentate in apical area, thence becoming thicker, denser, and multidentate toward basal area. SSp unidentate, short and small, covered almost of laterodorsal side and basal 1/3 of ventral side of PB. MSp area and LSp area adjacent. LSp area and SSp area close to each other.

Specimens Examined. 10", 1\%, Is. Nakanoshima, Tokara Isls., 7. VII, 1960, M. Satô leg.; $3 \sigma^{\top} \sigma^{\top}, 1$, , same locality, 21-22. VII, 1969, M. Sakai leg.; $10 \sigma^{\top} \sigma^{\top}$, 10우, same locality, 23. VI, 2003, J. Yamasako leg.

Distribution. Japan (Tokara Isls., Kagoshima Pref.; Is. IzuÔshima, Tokyo Pref.).

\subsubsection{Agelasta (Dissosira) konoi amamiana (Hayashi, 1962)} Comb. Nov.

Mesosa (Mesosa) konoi amamiana Hayashi, 1962: 13, pl. 3, Figure 11 [17].

Specimens Examined. 10, 1\%, Hatsuno, Is. Amami-Ôshima, 10. VII, 1962, N. Ohbayashi leg.; 1o, same locality, 29. VII, 1962, N. Ohbayashi leg.; 10, 19, same locality, 13. VI, 1962, M. Satô leg.; 10', Shinokawa, Is. Amami-Ôshima, 18. VI, 1997, S. Yoshimichi leg.

Distribution. Japan (Is. Amami-Ôshima, Kagoshima Pref.).
3.7.3. Agelasta (Dissosira) konoi okinoerabuensis (Ohbayashi, 1959), Comb. Nov.

Mesosa (Mesosa) konoi okinoerabuensis Ohbayashi, 1959: 3 [18].

Specimens Examined. $20^{\top} 0^{\top}, 1 \%$, Is. Okinoerabu, 6. VI, 1957, M. Umebayashi leg.; 1o, same locality, 13. VII, 1963, N. Ohbayashi leg.; $20^{7} \sigma^{7}$, same locality, 27. VI, 1964, M. Nishikawa coll.

Distribution. Japan (Is. Okinoerabu, Kagoshima Pref.).

3.7.4. Agelasta (Dissosira) konoi okinawana (Hayashi, 1960), Comb. Nov.

Mesosa (Mesosa) perplexa okinawana Hayashi, 1960: 27 [19].

Mesosa (Mesosa) konoi okinawana: Hayashi, 1962: 13 [17].

Mesosa (Saimia) cervinopicta: Gressitt, 1951: 220 (part.: Is. Okinawa, Japan) (nec Fairmaire, 1897) [20].

Specimens Examined. 10", Takari, Is. Okinawa, 29. VI, 1993, N. Ohbayashi leg.; 19, Mt. Yonahadake, Is. Okinawa, Okinawa Pref., Japan, 2. VII, 1993, N. Ohbayashi leg.

Distribution. Japan (Is. Okinawa, Okinawa Pref.).

3.7.5. Agelasta (Dissosira) konoi kumejimana (Kusama and Takakuwa, 1984) Comb. Nov.

Mesosa (Mesosa) konoi kumejimana Kusama and Takakuwa, 1984: 356 [21].

Specimen Examined. 10', Nakadomari, Is. Kumejima, Okinawa Pref., Japan, 25. III-30. VII, 1990, T. Ito leg.

Distribution. Japan (Is. Kumejima, Okinawa Pref.).

3.8. Agelasta (Dissosira) yonaguni (Hayashi, 1962), Comb. Nov.

Remarks. This species is distributed in the southwestern part of the Ryukyu Islands and is divided into four subspecies as described below. Here we limited the description to the nominotypical subspecies only, and that of the other subspecies are omitted.

3.8.1. Agelasta (Dissosira) yonaguni yonaguni (Hayashi, 1962) Comb. Nov. (Figures 4(a)-4(b), 6(e), 8(a)-8(d), and $10(\mathrm{a}))$

Mesosa (Mesosa) cervinopicta yonaguni Hayashi, 1962: 5, pl. 1, Figure 5 [22]. 


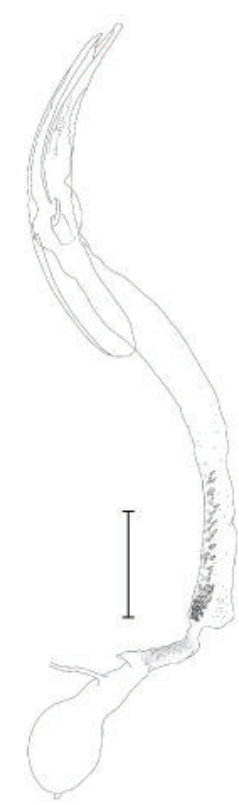

(a)

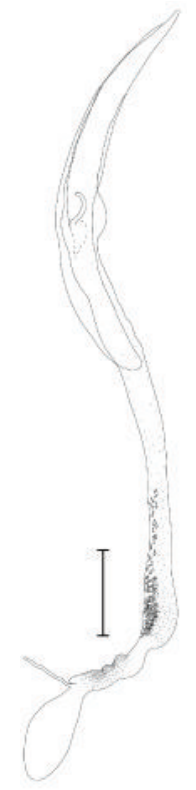

(b)

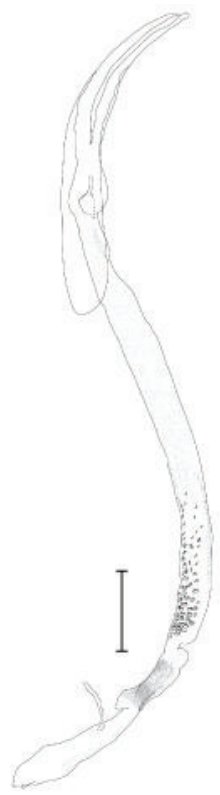

(c)

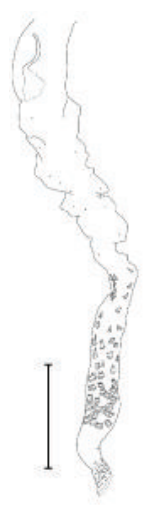

(d)

Figure 10: The median lobe with endophallus of Agelasta (Dissosira) spp. in lateral view. (a) A. (D.) yonaguni; (b) A. (D.) nigrostictica; (c) A. (D.) praelongipes; (d) A. (D.) kumei. Scale: $1.0 \mathrm{~mm}$.

Mesosa (Pachyosa) cervinopicta yonaguni: Samuelson, 1965: 100 [23].

Mesosa (Mesosa) yonaguni: Kusama and Irie, 1976: 20 [24].

Pachyosa cervinopicta: Miwa, 1935: 37 (Is. Yonaguni, Japan) (nec Fairmaire, 1897) [25].

Mesosa (Saimia) cervinopicta: Gressitt, 1951: 220 (nec Fairmaire, 1897) [20].

Diagnosis. This species is similar to A. perplexa, but distinguishable by the following features. Body black, mingled with yellowish ocher pubescence and black pubescence. Pronotum with disk with some irregular longitudinal black bands. Elytra mingled with yellowish ocher and black patches, of which yellowish ones are forming transversal irregular bands on post humeri, near middle, and near apical fourth. Prosternal process roundly truncated in lateral view.

Male Genitalia $(n=1)$. Tegmen in lateral view slightly curved, slender rhombic, and widest near middle in ventral view. Ringed part slightly expanded laterad near middle of tegmen, thence arcuately narrowed basad. Lateral lobes about $1 / 4$ of total length of tegmen, with inner sides almost straight, and outer sides gently narrowed to angularly rounded apex, provided with two kinds of setae of which one is long and thick, concentrated near apex, and another is rather short and thin, arising chiefly from outer sides of apical half.

Median lobe in lateral view gentry curved; apex in ventral view weakly pointed; median strut dehiscent from basal $1 / 3$.

Endophallus almost three times as long as median lobe in lateral view. The relative length of each broad membrane area of endophallus to median lobe are as follows: ML:TLE: $\mathrm{BPH}: \mathrm{MPH}(\mathrm{MT}+\mathrm{CT}: \mathrm{PB}): \mathrm{APH}=3.8: 10.0: 2.2: 6.0$ (5.1: $0.9): 1.8$. MPH with MT+CT well swollen and projected on ventral side near base. APH well swollen in oval shape, with ligulate-shaped AA near apex.

MSp distributed in nearly apical $2 / 3$ of MT+CT. LSp distributed in nearly basal $1 / 3$ of MT+CT on dorsal side, thick and short, arranged into two longitudinal irregular lines, unidentate in apical area, thence becoming thicker, denser and multidentate toward basal area. SSp unidentate, short and small, covered laterodorsal side of PB. MSp area and LSp area adjacent. LSp area and SSp area close to each other.

Specimens Examined. 107, Sonai, Is. Yonaguni, 10, V, 1963, Y. Arita leg.; 2o甲, Tendabaru, Is. Yonaguni, 13, V, 1963, Y. Arita leg.; 2oㅇ, Tabaru-gawa, Is. Yonaguni, 14, V, 1963, Y. Arita leg.; 5우, Mt. Urabedake, Is. Yonaguni, 6-7, VII, 1969, Y. Hori leg.; 2oㅇ, same locality, 11. VII, 1964, N. Ohbayashi leg.; 10, Hikawa, Is. Yonaguni, Okinawa Pref, Japan, 16. V, 1963, Y. Arita leg.; $10^{7}$, Mt. Urabedake, Is. Yonaguni, Okinawa Pref, Japan, 20. V, 1989, N. Ohbayashi leg.

Distribution. Japan (Is. Yonaguni, Okinawa Pref.).

3.8.2. Agelasta (Dissosira) yonaguni subkonoi (Hayashi, 1962) Comb. Nov.

Mesosa (Mesosa) subkonoi Breuning, 1964: 91 [26].

Mesosa (Mesosa) cervinopicta cervinopicta f. subkonoi: Hayashi, 1964: 70, Figure 1 [27]. 
Mesosa (Mesosa) yonaguni subkonoi: Kusama and Irie, 1976: 20, Figures 3(a) and 3(b) [24].

Mesosa (Mesosa) perplexa: Hayashi, 1962: 32 (nec Pascoe, 1858) [16].

Pachyosa cervinopicta: Miwa, 1933: 12 (nec Fairmaire, 1897) [28].

Mesosa (Saimia) cervinopicta: Gressitt, 1951: 220 (nec Fairmaire, 1897) [20].

Mesosa (Mesosa) cervinopicta cervinopicta: Hayashi, 1962: 35, pl. 4, Figure 3 (nec Fairmaire, 1897) [15].

Specimens Examined. [Is. Ishigaki, Okinawa Pref., Japan]: $30^{7} \sigma^{7}, 1$, , Kawarayama, 29. VI, 1964, N. Ohbayashi leg.; Arakawa, 16. VI, 1965, K. Hatta leg.; 2oㅇ, Nosoko-dake, 21. VII, 1998, A. Komada leg. [Is. Iriomote, Okinawa Pref., Japan]: $20^{\top} \sigma^{7}, 1$, , Ushikuno-mori, 7. VIII, 1962, Y. Arita and M. Satô leg.; 1\%, same locality, 26. VI, 1965, Y. Hori leg.; 107, Sonai, 24. VI, 1965, Y. Hori leg.

Distribution. Japan (Is. Ishigaki, Is. Iriomote and Is. Taramajima, Okinawa Pref.).

3.8.3. Agelasta (Dissosira) yonaguni kashiwaii (Kusama and Takakuwa, 1984), Comb. Nov.

Mesosa (Mesosa) yonaguni kashiwaii Kusama and Takakuwa, 1984: 11, 358 [21].

Mesosa (Mesosa) cervinopicta f. subkonoi: Hayashi and Nomura, 1964: 67 (Is. Hateruma, Japan) (nec Breuning, 1964) [29].

Mesosa (Mesosa) yonaguni subkonoi: Kusama and Irie, 1976: 20 (part.: Is. Hateruma) (nec Breuning, 1964) [24].

Specimens Examined. $30^{7} \sigma^{7}, 1$, Is. Hateruma, 26. IV, 1975, K. Shimizu leg.

Distribution. Japan (Is. Taketomi, Is. Kohama, Is. Kuroshima and Is. Hateruma, Okinawa Pref.).

\subsubsection{Agelasta (Dissosira) yonaguni similaris (Kusama and} Takakuwa, 1984), Comb. Nov.

Mesosa (Mesosa) yonaguni similaris Kusama and Takakuwa, 1984: 11 [21].

Pachyosa cervinopicta: Matsushita, 1933: 344 (nec Fairmaire, 1897) [10].

Mesosa (Saimia) cervinopicta: Hayashi, 1960: 27 (nec Fairmaire, 1897) [19].

Mesosa (Pachyosa) cervinopicta cervinopicta: Samuelson, 1965: 99 (nec Fairmaire, 1897) [23].

Mesosa (Mesosa) yonaguni subkonoi: Kusama and Irie, 1976: 20 (nec Breuning, 1964) [24].
Mesosa (Mesosa) yonaguni semipraelongipes Kusama and Takakuwa, 1984: 358, errata [21].

Specimens Examined. 10" Hirara-shi, Is. Miyako, 14. VII, 2001, N. Ohshige leg.; 10', Is. Tarama, 1. VI, 1993, H. Kanazawa leg.

Distribution. Japan (Is. Miyako, Is. Irabu, Is. Ikema, Is. Ôgami and Is. Tarama of Miyako Isls., Okinawa Pref.).

3.9. Agelasta (Dissosira) nigrostictica (Breuning, 1967), Comb. Nov. (Figures 4(c)-4(d), 6(f), 8(e)-8(h), and $10(\mathrm{~b}))$

Mesosa (Mesosa) nigrostictica Breuning, 1967: 185 [30].

Diagnosis. This species is similar to A. catenata, but distinguishable by the following features. Body black or reddish brown, evenly covered with light brown pubescence. Antennae with each basal part of third to sixth or seventh segments with white pubescent annulations, which are getting narrower toward apical segment; the reminders covered with black pubescence. Pronotum with two indistinct longitudinal narrow black bands on disk. Elytra with two pairs of black fragment maculae on lateral side before and after middle. Prosternal process roundly sloped and not truncate in lateral view.

Male Genitalia $(n=1)$. Tegmen in lateral view slightly curved, rhombic, and widest near middle in ventral view. Ringed part slightly expanded laterad near middle of tegmen, thence arcuately narrowed basad. Lateral lobes about $1 / 4$ of total length of tegmen, with inner sides almost straight, and outer sides nearly straight toward apical third, thence gentry narrowed to rounded apex, provided with two kinds of setae of which one is long and thick, concentrated near apex, and another is rather short and thin, sparsely distributed in ventral side, apical third of laterodorsal sides; each ventral side near base with a transversal obtuse ridge which is haired in mass on the edge of ridge.

Median lobe in lateral view gentry curved; apex in ventral view weakly pointed; median strut dehiscent from basal 2/5.

Endophallus about 2.5 times as long as median lobe in lateral view. The relative length of each broad membrane area of endophallus to median lobe is as follows: $\mathrm{ML}$ : TLE : BPH : MPH (MT+CT : PB) : APH = 4.3: $10.0: 2.5: 6.2$ $(5.3: 0.9): 1.2$. MPH with $\mathrm{MT}+\mathrm{CT}$ well swollen and weakly projected on ventral side near base. APH well swollen in oval shape, with ligulate-shaped AA near apex, which is relatively indistinct.

MSp sparsely distributed in nearly apical half of MT+CT. LSp on dorsal side distributed in nearly basal half of MT+CT, thick and short, arranged into two longitudinal irregular lines, unidentate in apical area, thence becoming thicker, denser, and multidentate toward basal area; LSp on ventral side irregularly distributed in nearly basal $1 / 3$ of MT+CT, 
short, indistinct and rudimentary unidentate. SSp unidentate, short and small, covered almost of laterodorsal side and basal 1/3 of ventral side of PB. MSp area and LSp area adjacent. LSp area and SSp area close to each other.

Specimens Examined. [Java, Indonesia]: Photographs of the holotype (MNHN): 10", "Mesosa/nigrostictica/mihi typ/Breuning dét." [printed on white label], "TYPE" [printed on red label], "MUSÉUM PARIS/1952/COLL R OBERTHUR" [printed on white label margined with black line], "Java/ Malang" [printed on white label margined with black line]. [Bali, Indonesia]: 107, Bali, Indonesia, 30. V, 1998, Native

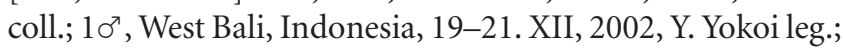
$10^{7}$, Bali, Indonesia, X, 2005, Native leg.

Distribution. Indonesia (Java, Bali).

Remarks. This is first record of this species from Is. Bali. The male genital features above are described based on the specimen from Is. Bali.

\subsection{Agelasta (Dissosira) siamana (Breuning, 1974), Comb. Nov. (Figure 5(e))}

Mesosa (Mesosa) siamana Breuning, 1974: 73 [31].

Diagnosis. This species is very similar to A. columba, but distinguishable by the following features. Body black, covered with light brown pubescence. Antennae with each basal part of third to the last segments with white pubescent annulations, which are getting narrower toward the last segment; the reminders covered with black pubescence. Pronotum with two pair of small longitudinal black maculae on disk. Elytra with indistinct transversal white band near middle, scattered with several brown spots.

Specimen Examined. Photographs of a syntype (MNHN): $10^{7}$, "Mesosa/siamana/mihi typ/Breuning dét." [printed on white label], "TYPE” [printed on red label], "Siam” [printed on white label], "MUSEUM PARIS/COLL. H. W. BATES/ 1952" [printed on white label margined with black line].

\section{Distribution. Thailand.}

\subsection{Agelasta (Dissosira) praelongipes (Kusama and Irie, 1976), Comb. Nov. (Figures 4(e)-4(f), 6(g), $8(\mathrm{i})-8(\mathrm{l})$, and $10(\mathrm{c}))$}

Mesosa (Mesosa) praelongipes Kusama and Irie, 1976: 20, Figures 2(a) and 2(b) [24].

Diagnosis. This species is very similar to A. (D.) yonaguni, but distinguishable by the following features. Prosternal process nearly truncated in lateral view. Fore legs of male distinctly longer than female. Seventh abdominal sternite twice as long as the sixth; pygidium distinctly exposed from the apices of elytra in male. The pubescence on abdominal sternites sparsely arranged or almost disappeared.

Male Genitalia $(n=2)$. Tegmen in lateral view slightly curved, rhombic, and widest near middle in ventral view. Ringed part slightly expanded laterad near middle of tegmen, thence arcuately narrowed basad. Lateral lobes about $1 / 3$ of total length of tegmen, with inner side almost straight, and outer side expanded toward apical $4 / 5$, thence obliquely narrowed to angularly rounded apex, provided with two kinds of setae of which one is long and thick, concentrated near apex, and another is rather short and thin, arising chiefly from outer sides of apical half.

Median lobe in lateral view gentry curved; apex in ventral view weakly pointed; median strut dehiscent from basal half.

Endophallus almost three times as long as median lobe in lateral view. The relative length of each broad membrane area of endophallus to median lobe is as follows: ML:TLE: $\mathrm{BPH}: \mathrm{MPH} \quad(\mathrm{MT}+\mathrm{CT}: \mathrm{PB}): \mathrm{APH}=$ $3.5: 10.0: 2.5: 6.0(5.2: 0.8): 1.5$. MPH with MT+CT well swollen and projected on ventral side near base. APH swollen in elongate oval shape, with ligulate-shaped AA near apex.

MSp distributed in nearly apical $2 / 3$ of MT+CT. LSp on dorsal side distributed in nearly basal $1 / 3$ of MT+CT, thick and short, arranged into two longitudinal irregular lines, unidentate in apical area, thence becoming thicker, denser and multidentate toward basal area; LSp on ventral side irregularly distributed in nearly basal $1 / 3$ of $\mathrm{MT}+\mathrm{CT}$, short and rudimentary unidentate. SSp unidentate, short and small, covered basal 3/4 of PB. MSp area and LSp area adjacent. LSp area and SSp area close to each other.

Specimens Examined. 107, 19, Uinpia, Is. Miyako, 30-31. V, 1975, H. Makihara leg.; $50^{7} 0^{7}$, 3o+ Miyako, 7. VIII, 1999, T. Mizoguchi leg.; 10, 19, Is. Kurima, collected the logs at III, 1996 and emerged on VI, 1996, K. Shimizu leg.; $10^{7}$, same locality, IV, 2003, K. Shimizu leg.

Distribution. Japan (South area of Is. Miyako and Is. Kurima of Miyako Isls., Okinawa Pref.).

3.12. Agelasta (Dissosira) kumei (Takakuwa, 1991), Comb. Nov. (Figures 4(g)-4(h), 6(h), 8(m)-8(p), and 10(d))

Mesosa (Mesosa) kumei Takakuwa, 1991: 51, illustration [32].

Diagnosis. This species is similar in the appearance to $A$. konoi or A. perplexa, but distinguishable by its large body size. Body black, covered with yellowish light ocher pubescence. Occiput with four longitudinal narrow black bands. Pronotum with three longitudinal black bands on disk. Elytra with three transversal yellowish white bands on behind humeri, near middle, and near apices. Pronotum with three rudimentary tubercles on disk. Prosternal process rounded in lateral view, and not truncate at the apex. 
Male Genitalia ( $n=1$, Partly Broken). Tegmen in lateral view slightly curved, slender rhombic, and widest near middle in ventral view. Ringed part weakly expanded laterad near middle of tegmen, thence arcuately narrowed to basad. Lateral lobes slightly narrowed toward rounded apex, provided with two kinds of setae of which one is long and thick, concentrated on the apex, and another is rather short, thin, mainly arising from apical half.

Median lobe with apex roundly pointed in ventral view.

Basal half of endophallus is lost. LSp thick and short, arranged into two longitudinal irregular lines on dorsal side of MT+CT, unidentate in apical area, thence becoming thicker, denser, and multidentate toward basal area.

Specimens Examined. 1\%, Is. Lu-dao, Taitung county, Taiwan, 16-20. VI, 1989, Native leg.; 2oㅇ, same locality, 510. VII, 1989, Native leg.; 10", Gangguan, alt. 0-10 m, same island, 5. IV, 2004, T. Kurihara leg.

\section{Distribution. Taiwan (Is. Lu-Dao).}

Remarks. The male genitalia of the examined specimen was partly broken, and we could not observe the basal half of median lobe and the basal part of endophallus. However, this species basically shares the external features, the shape of the tegmen of the male genitalia, and the characteristics of LSp of the endophallus with A. konoi or A. yonaguni and A. perplexa. It suggests that this species is closely related to these species. Therefore, we treat this species as a member of Agelasta (Dissosira).

\section{Discussion}

Among the species which have been classified into the nominotypical subgenus of Mesosa, 12 species distributed in the Oriental region are different from Mesosa (Mesosa) and have close relationship with Agelasta (Dissosira).

The genera Mesosa and Agelasta have mainly been distinguished from each other by the prosternal process, rounded or truncated in lateral view (e.g., Breuning [2]). The shape of the prosternal process is essentially stable in the Mesosini group, and it is worth defining the genera or subgenera by the external features. However, this structure is exceptionally variable and unstable in some groups of the genus Agelasta. Therefore, several species included in Mesosa have been confused with Agelasta, especially Agelasta (Dissosira), because of this variable structure (Yamasako and Ohbayashi [4]). Yamasako and Ohbayashi $[4,5]$ had already pointed out that the basic structure of the endophallus is very useful for defining the groups of Mesosini such as the genera or subgenera. Also, it is considered to be useful for analysis of the phylogenetic relationship. Therefore, the generic definition of Mesosini should be decided by the combination of the external and the genital features.

According to this point of view, the genus Agelasta is essentially distinguishable from Mesosa by the following characteristics: (1) antennal scape elongate, slightly thickened apicad, (2) lower lobes of eyes relatively large, (3) endophallus with LSp on the dorsal side arranged into two irregular longitudinal lines, unidentate in apical area, thence becoming thicker, denser and multidentate toward the basal area, rudimentary unidentate or almost disappeared on the ventral side, almost without AS. These differences suggest that the genera Agelasta and Mesosa are different phyletic groups.

On the basis of these characteristics, we transferred 12 species to Agelasta (Dissosira) that were previously classified into Mesosa (Mesosa) in spite of their rounded prosternal process in lateral view. They should be included in Agelasta (Dissosira) (sens. str. by Yamasako and Ohbayashi [4]) because they share external features and endophallic structures with the type species of the subgenus, $A$. (D.) catenata.

Agelasta (Dissosira) is widely distributed in the Oriental geographic region except for the Philippines, and its distribution extends northwardly to the Tokara Islands of Japan which is the northern end of the Oriental region.

\section{Appendix}

The examined specimen data for the type species of Mesosa (Mesosa) and Agelasta (Dissosira) in this study.

\section{Mesosa (Mesosa) curculionoides}

Specimens Examined. 10", Vestec, Czech, 30. V, 1946, Lenesch leg.; 10', 19, Leitha-Geb., b. Eisenstadt, 6. VI, 1976, BGLD; $30^{7} 0^{7}$, Olympie-Péloponèse, Greece, 2. VII, 1981, A. Le Restif leg.; 10", Murauen, b. Mureck, 14. V, 1983, S-STMK; $10^{7}$, Góry, Plock Dist., Poland, 18. V, 2002, M. Szewczyk leg.; 1o, same locality, 20. V, 2003, M. Szewczyk leg.

\section{Agelasta (Dissosira) catenata}

Specimens Examined. 10', 1\%, Sayaboury, Laos, 14. VII. 1965, J. A. Rondon leg.; Same locality and collector, 9. VIII. 1965; 107, Ban Van Heua, Vientiane, Laos, 15. VIII. 1965 J. A. Rondon leg.; 1q, Ile de Khong, Laos, 15. IV. 1965 J. A. Rondon leg.

\section{Abbreviations}

AA: Appendix of apical bulb

APH: Apical phallomer

AS: Sclerite of apical phallomer

BPH: Basal phallomer

CS: Crescent shaped sclerites

CT: Central trunk

LSp: Large spicules

ML: Median lobe

MPH: Median phallomer

MSp: Micro spicules

MT: Medial tube

PB: Preapical bulb

SSp: Small spicules

TLE: Total length of endophallus. 


\section{Acknowledgments}

Junsuke Yamasako would like to thank Professor Masahiro Sakai and Associate Professor Hiroyuki Yoshitomi of EUMJ for their kind guidance and constant encouragement. Also, the authors are greatly indebted to Dr. Axel Hausmann and Dr. Ulf Buchsbaum (ZSM), Mr. Gérard Tavakilian (MNHN), and Ms. Sharon Shute (BMNH) for all their trouble in our investigation or for taking photographs of the type specimens preserved in their institute. They are much obliged to Drs. Kiyoshi Ando, Wen-I Chou, Michiaki Hasegawa, Sadatomo Hisamatsu, Takashi Kurihara, Tatsuya Niisato, Akiko Saito, Eduard Vives, Messrs. Shusei Saito, Yu Long Lin, Kazuki Mori, Shigeo Tsuyuki, and Yaheita Yokoi for their kind help for this study, and Mr. Dennis Murphy (The United Graduate School of Agricultural Sciences, Ehime University) for his critical reading of the paper.

\section{References}

[1] P. A. Latreille, Les Crustacés, les Arachnides et les Insectes, Distribués en Familles Naturelles, Ouvrage Formant les Tomes 4 et 5 de Celui de M. le Baron Cuvier sur le Règne Animal, Déterville, Paris, deuxième edition, 1829.

[2] S. Breuning, "Études sur les Lamiaires: Huitième tribu: Mesosini Thomson (Col., Cerambycidae)," Novitates Entomologica, pp. 365-526, 1938-1940.

[3] J. Yamasako and N. Ohbayashi, "A review of the Japanese species of the lamiine subgenus Perimesosa of the genus Mesosa (Coleoptera, Cerambycidae) [Studies of Asian Mesosini, I]," The Japanese Journal of Systematic Entomology, vol. 13, no. 2, pp. 333-348, 2007.

[4] J. Yamasako and N. Ohbayashi, "Systematic position of the subgenus Anthriboscyla Thomson of the genus Mesosa (Coleoptera, Cerambycidae) [Studies of Asian Mesosini, IV]," The Japanese Journal of Systematic Entomology, vol. 15, no. 2, pp. 415-421, 2009.

[5] J. Yamasako and N. Ohbayashi, "Review of the genus Paragolsinda Breuning, 1956 (Coleoptera, Cerambycidae, Lamiinae, Mesosini), with reconsideration of the endophallic terminology," Zootaxa, no. 2882, pp. 35-50, 2011.

[6] F. P. Pascoe, "Longicornia Malayana, or a descriptive catalogue of the species of the three longicorn families Lamiidae, Cerambycidae and Prionidae, collected by Mr. A. R. Wallace in the Malay Archipelago," The Transactions of the Entomological Society of London, vol. 3, no. 6, pp. 497-710, 1864-1869.

[7] C. Aurivillius, "Cerambycidae: lamiinae I, Pars 73," in Coleopterorum Catalogus, S. Schenkling, Ed., pp. 1-322, W. Junk, Berlin, Germany, 1922.

[8] J. Thomson, "Matériaux pour servir à une révision des lamites (cérambycides, Col.)," Physis, vol. 2, no. 6, pp. 146-200, 1868.

[9] S. Breuning, "Novae species cerambycidarum. IV" Folia Zoologica et Hydrobiologica, vol. 8, no. 2, pp. 251-276, 1935.

[10] M. Matsushita, "Beitrag zur Kenntnis der Cerambyciden des japanischen Reichs," Journal of the Faculty of Agriculture of the Hokkaido Imperial University, vol. 34, no. 2, pp. 157-455, 1933.

[11] B. Schwarzer, "Sauters formosa-ausbeute (Cerambycidae. Col.). (Subfamilie Lamiinae.) (Fortsetzung.)," Entomologische Blätter, vol. 21, pp. 58-68, 1925.

[12] M. Pic, "Nouveautés diverses," Mélanges Exotico Entomologiques, vol. 44, pp. 1-32, 1925.

[13] N. Ohbayashi, "Taxonomic notes on Japanese Cerambycidae
(Coleoptera)," Acta Coleopterologica Japonica, vol. 2, pp. 1-11, 1992.

[14] S. Breuning, "Novae species cerambycidarum VI," Festschrift zum 60. Geburtstage von Professor Dr. Embrik Strand, vol. 4, pp. 180-392, 1938.

[15] M. Hayashi, "Entomological results from the scientific survey of the Tokara Islands V. Coleoptera: cerambycidae," Bulletin of the Osaka Municipal Museum of Natural History, vol. 9, pp. 11-12, 1956.

[16] M. Hayashi, "The Cerambycidae of Japan (Col.) (5)," The Entomological Review of Japan, vol. 15, no. 1, pp. 25-36, 1962 (Japanese).

[17] M. Hayashi, "The Cerambycidae from Amami-Ôshima Islands. II. Additions to the cerambycid-fauna of the LoochooArchipelago. 2 (Col.)," The Entomological Review of Japan, vol. 14, no. 1, pp. 8-18, 1962.

[18] K. Ohbayashi, "New cerambycidae from Japan, (5)," The Entomological Review of Japan, vol. 10, no. 1, pp. 1-3, 1959.

[19] M. Hayashi, "Additions to the Cerambycid-fauna of the Loochoo-Archipelago (Col.) (1)," The Entomological Review of Japan, vol. 11, no. 1, pp. 21-29, 1960.

[20] J. L. Gressitt, "Longicorn Beetles from the Ryukyu Islands (Coleoptera: Cerambycidae)," The Philippine Journal of Science, vol. 79, no. 2, pp. 193-235, 1951.

[21] K. Kusama and M. Takakuwa, The Longicorn-Beetles of Japan in Color, The Japanese Society of Coleopterology, Tokyo, Japan, 1984.

[22] M. Hayashi, "The cerambycidae of ryukyu-islands. I. Additions to the cerambycid-fauna of Ryukyu Archipelago. 3 (Col.)," The Entomological Review of Japan, vol. 15, no. 1, pp. $1-8,1962$.

[23] G. A. Samuelson, "The cerambycidae (Coleopt.) of the Ryukyu Archipelago II, Lamiinae," Pacific Insects, vol. 7, no. 1, pp. 82130, 1965.

[24] K. Kusama and H. Irie, "Notes on the longicorn genus Mesosa. Two new species and others from Nansei Islands of Japan," Elytra, vol. 3, no. 1-2, pp. 19-23, 1976.

[25] Y. Miwa, "Coleoptera of Yonaguni Island. (Coleopteran fauna of Loo-Choo)," Mushi, vol. 8, no. 1, pp. 37-38, 1935 (Japanese).

[26] S. Breuning, "Neue Lamiiden aus dem Museum G. Frey (Col. Cerambycidae)," Entomologischen Arbeiten aus dem Museum G. Frey, Tutzing bei München, vol. 15, pp. 91-97, 1964.

[27] M. Hayashi, "The cerambycidae of Japan (Col.) (6)," The Entomological Review of Japan, vol. 17, no. 2, pp. 69-76, 1964 (Japanese).

[28] Y. Miwa, "An enumeration of Coleoptera from the island Iriomote in Loo-Choo, with description of new species," Transactions of the Natural History Society of Formosa, vol. 23, no. 124, pp. 4-15, 1933.

[29] M. Hayashi and H. Nomura, "Cerambycidae from Is. Hateruma, Yayeyama Isl., S. Ryukyu (Col.),” The Entomological Review of Japan, vol. 17, no. 2, pp. 67-68, 1964.

[30] S. Breuning, "Nouveaux Cerambycidae Lamiinae des collections du Muséum national d'Histoire naturelle de Paris [Col.]," Bulletin de la Société Entomologique de France, vol. 72, pp. 183-189, 1967.

[31] S. Breuning, "Nouveaux Mesosini des collections du Muséum national d'Histoire naturelle [Col. Cerambycidae Lamiinae]," Bulletin de la Société Entomologique de France, vol. 79, pp. 7279, 1974.

[32] M. Takakuwa, "Two new cerambycid beetles from Lutao Island off Southwest Taiwan," Bulletin of the Kanagawa prefecture Museum (Natural Sciences), no. 20, pp. 51-58, 1991. 

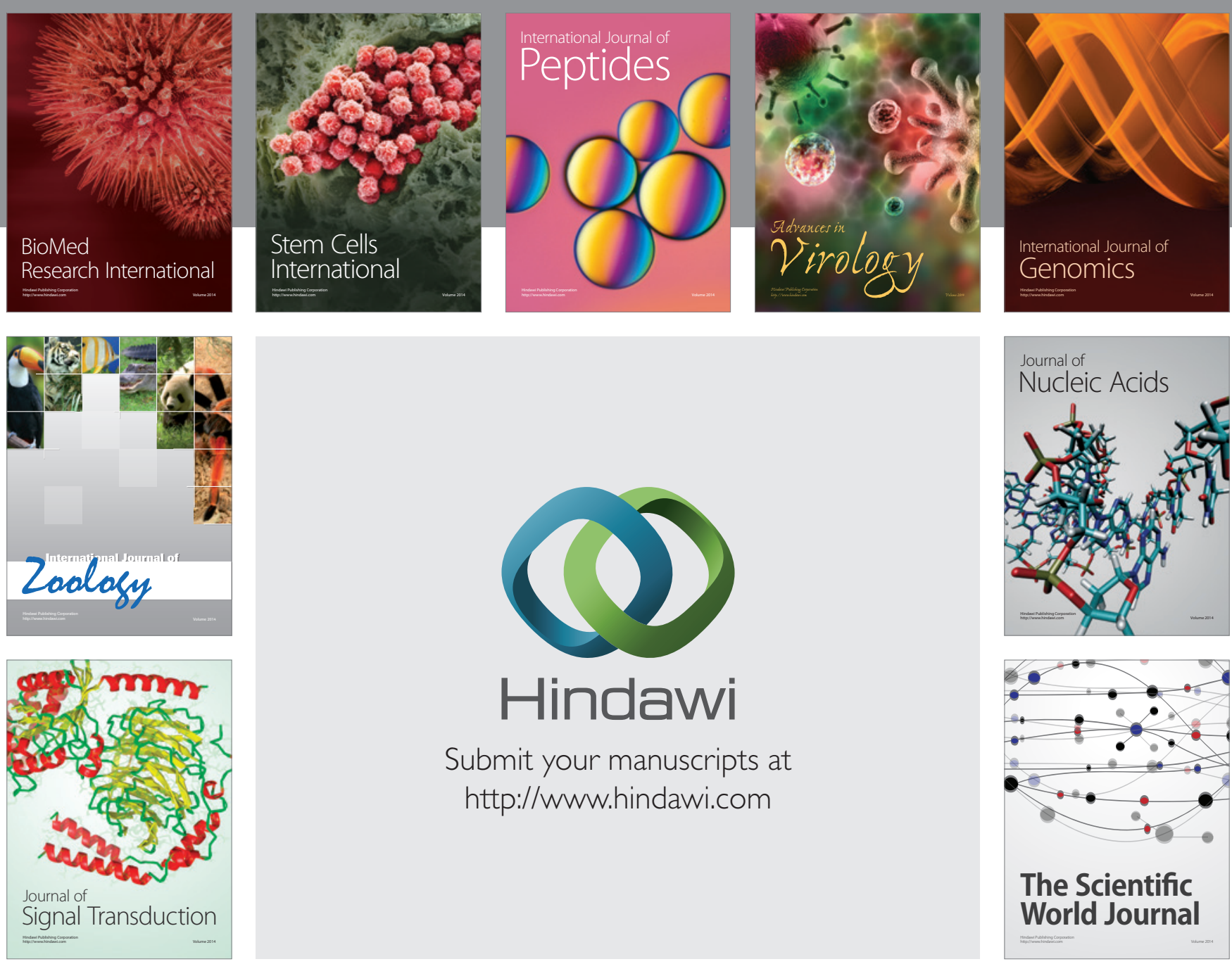

Submit your manuscripts at

http://www.hindawi.com
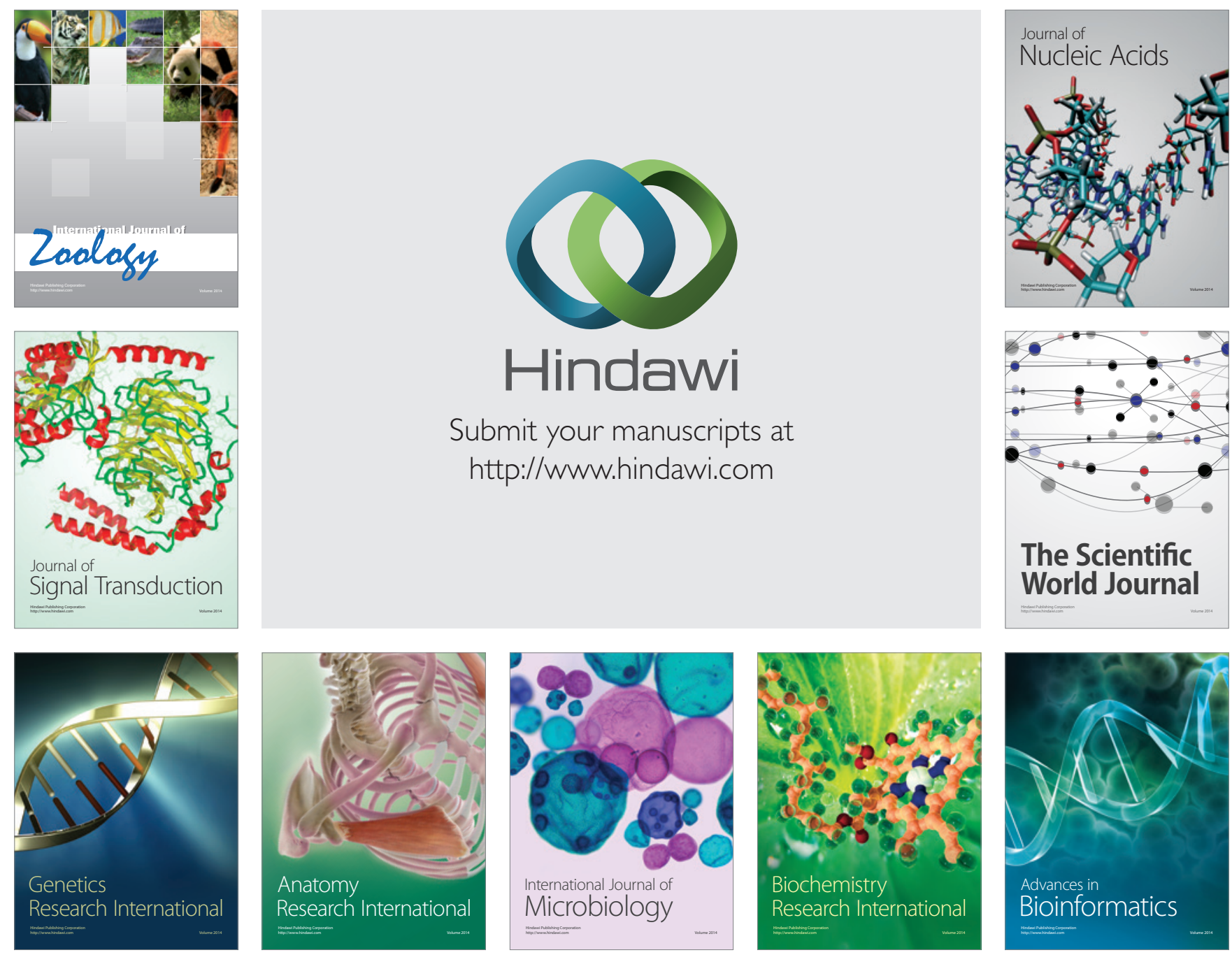

The Scientific World Journal
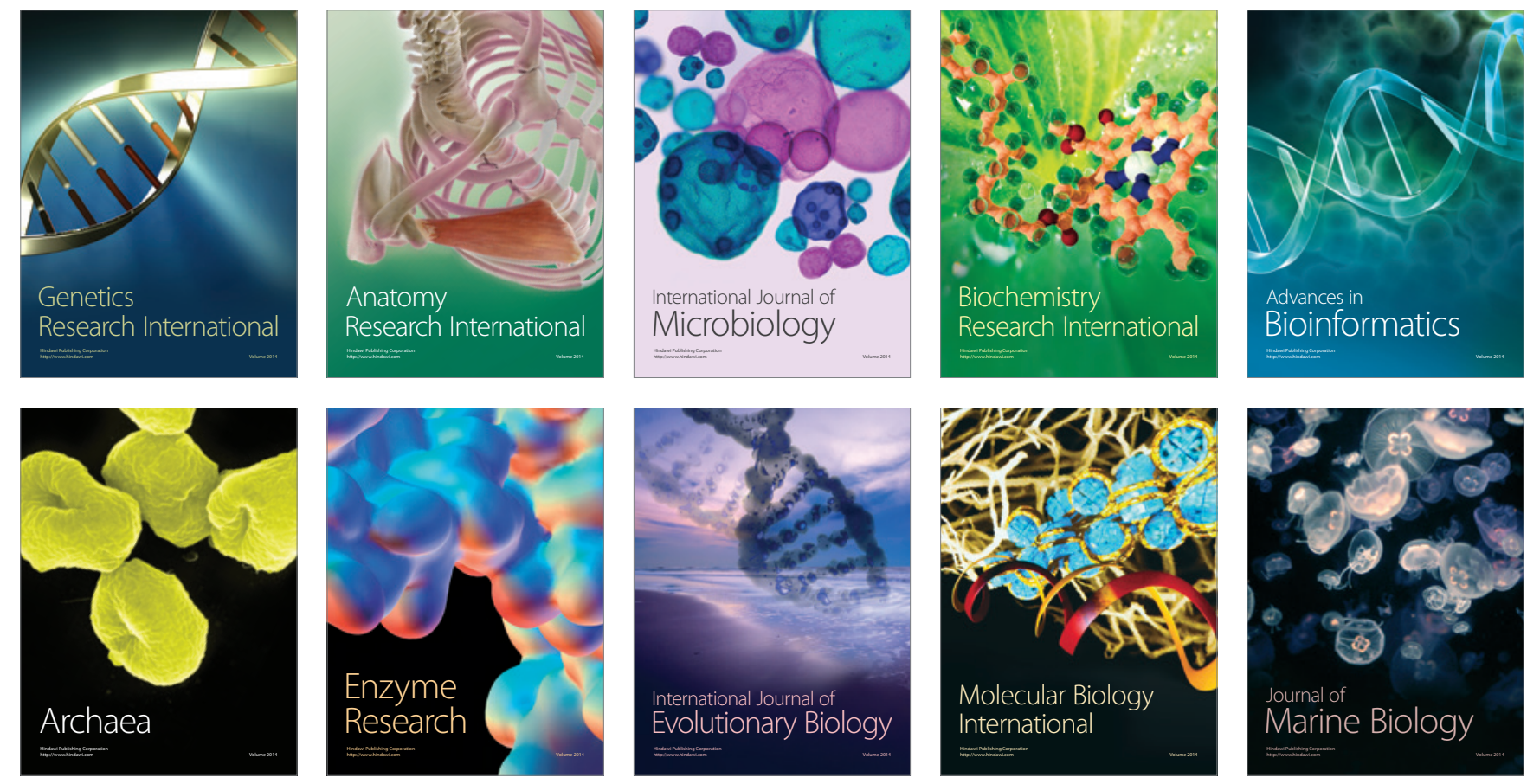